\title{
Some fixed point results for multi-valued mappings in partial metric spaces
}

\author{
Jamshaid Ahmad' ${ }^{1}$, Cristina Di Bari ${ }^{2}$, Yeol Je Cho $^{3 *}$ and Muhammad Arshad ${ }^{4}$
}

\footnotetext{
"Correspondence: yjcho@gnu.ac.kr ${ }^{3}$ Department of Mathematics Education and RINS, Gyeongsang National University, Jinju, 660-701, Korea

Full list of author information is available at the end of the article
}

\begin{abstract}
In this paper, we obtain some fixed point results for multi-valued mappings in partial metric spaces. Our results unify, generalize and complement various known comparable results from the current literature. An example is also included to illustrate the main result in the paper.
\end{abstract}

MSC: $46 \mathrm{~S} 40 ; 47 \mathrm{H} 10 ; 54 \mathrm{H} 25$

Keywords: partial Hausdorff metric; multi-valued mapping; fixed point; completeness

\section{Introduction and preliminaries}

The fixed point theory is one of the most powerful and fruitful tools in nonlinear analysis. Its core subject is concerned with the conditions for the existence of one or more fixed points of a mapping $T$ from a topological space $X$ into itself, that is, we can find $x \in X$ such that $T x=x$. The Banach contraction principle [1] is the simplest and one of the most versatile elementary results in fixed point theory. Moreover, being based on an iteration process, it can be implemented on a computer to find the fixed point of a contractive mapping. It produces approximations of any required accuracy, and, moreover, even the number of iterations needed to get a specified accuracy can be determined. Recently, Samet et al. [2] introduced a new concept of $\alpha$-contractive type mappings and established various fixed point theorems for such mappings in complete metric spaces. The presented theorems extend, generalize and improve several results on the existence of fixed points in the literature.

In 1994, Matthews [3] introduced the concept of a partial metric space and obtained a Banach-type fixed point theorem on complete partial metric spaces. Later on, several authors (see, for example, [4-31]) proved fixed point theorems in partial metric spaces. After the definition of the partial Hausdorff metric, Aydi et al. [28] proved the Banach-type fixed point result for set-valued mappings in complete partial metric spaces.

The aim of this paper is to generalize various known results proved by Nadler [32], Kikkawa and Suzuki [33], Mot and Petrusel [34], Dhompongsa and Yingtaweesittikul [35] to the case of partial metric spaces and give one example to illustrate our main results.

We start with recalling some basic definitions and lemmas on partial metric spaces. The definition of a partial metric space is given by Matthews [3] (see also [7, 29, 30]) as follows.

o 2013 Ahmad et al.: licensee Springer. This is an Open Access article distributed under the terms of the Creative Commons Attribution License (http://creativecommons.org/licenses/by/2.0), which permits unrestricted use, distribution, and reproduction in any medium, provided the original work is properly cited. 
Definition 1 A partial metric on a nonempty set $X$ is a function $p: X \times X \rightarrow[0,+\infty)$ such that the following conditions hold: for all $x, y, z \in X$,

( $\left.\mathrm{P}_{1}\right) p(x, x)=p(y, y)=p(x, y)$ if and only if $x=y$,

$\left(\mathrm{P}_{2}\right) p(x, x) \leq p(x, y)$

$\left(\mathrm{P}_{3}\right) p(x, y)=p(y, x)$,

$\left(\mathrm{P}_{4}\right) p(x, z) \leq p(x, y)+p(y, z)-p(y, y)$.

The pair $(X, p)$ is then called a partial metric space.

If $(X, p)$ is a partial metric space, then the function $p^{s}: X \times X \rightarrow[0,+\infty)$ given by $p^{s}(x, y)=2 p(x, y)-p(x, x)-p(y, y)$ for all $x, y \in X$ is a metric on $X$.

A basic example of a partial metric space is the pair $([0,+\infty), p)$, where $p(x, y)=\max \{x, y\}$ for all $x, y \in[0,+\infty)$.

Lemma 1 Let $(X, p)$ be a partial metric space, then we have the following:

(1) A sequence $\left\{x_{n}\right\}$ in a partial metric space $(X, p)$ converges to a point $x \in X$ if and only if $\lim _{n \rightarrow+\infty} p\left(x, x_{n}\right)=p(x, x)$.

(2) A sequence $\left\{x_{n}\right\}$ in a partial metric space $(X, p)$ is called a Cauchy sequence if the $\lim _{n, m \rightarrow+\infty} p\left(x_{n}, x_{m}\right)$ exists and is finite.

(3) A partial metric space $(X, p)$ is said to be complete if every Cauchy sequence $\left\{x_{n}\right\}$ in $X$ converges to a point $x \in X$, that is, $p(x, x)=\lim _{n, m \rightarrow+\infty} p\left(x_{n}, x_{m}\right)$.

(4) $\left\{x_{n}\right\}$ is a Cauchy sequence in $(X, p)$ if and only if it is a Cauchy sequence in the metric space $\left(X, p^{s}\right)$.

(5) A partial metric space $(X, p)$ is complete if and only if the metric space $\left(X, p^{s}\right)$ is complete. Furthermore, $\lim _{n \rightarrow+\infty} p^{s}\left(x_{n}, z\right)=0$ if and only if

$$
p(z, z)=\lim _{n \rightarrow+\infty} p\left(x_{n}, z\right)=\lim _{n, m \rightarrow+\infty} p\left(x_{n}, x_{m}\right) .
$$

Remark 1 ([7], Lemma 1) Let $(X, p)$ be a partial metric space and let $A$ be a nonempty set in $(X, p)$, then $a \in \bar{A}$ if and only if

$$
p(a, A)=p(a, a)
$$

where $\bar{A}$ denotes the closure of $A$ with respect to the partial metric $p$. Note $A$ is closed in $(X, p)$ if and only if $\bar{A}=A$.

Now, we state the following definitions and propositions of a very recent paper of Aydi et al. [28].

Let $C B^{p}(X)$ be a collection of all nonempty closed and bounded subsets of $X$ with respect to the partial metric $p$. For any $A \in C B^{p}(X)$, we define

$$
p(a, A)=\inf \{p(a, x): x \in A\} .
$$

On the other hand, for any $A, B \in C B^{p}(X)$, we define

$$
\begin{aligned}
& \delta_{p}(A, B)=\sup \{p(a, B): a \in A\}, \\
& \delta_{p}(B, A)=\sup \{p(b, A): b \in B\}
\end{aligned}
$$


and

$$
H_{p}(A, B)=\max \left\{\delta_{p}(A, B), \delta_{p}(B, A)\right\} .
$$

Proposition 1 [28] Let $(X, p)$ be a partial metric space. For any $A, B, C \in C B^{p}(X)$, we have

(1) $\delta_{p}(A, A)=\sup \{p(a, a): a \in A\}$.

(2) $\delta_{p}(A, A) \leq \delta_{p}(A, B)$.

(3) $\delta_{p}(A, B)=0$ implies that $A \subseteq B$.

(4) $\delta_{p}(A, B) \leq \delta_{p}(A, C)+\delta_{p}(C, B)-\inf _{c \in C} p(c, c)$.

Proposition $2[28]$ Let $(X, p)$ be a partial metric space. For any $A, B, C \in C B^{p}(X)$, we have

(1) $H_{p}(A, A) \leq H_{p}(A, B)$

(2) $H_{p}(A, B)=H_{p}(B, A)$.

(3) $H_{p}(A, B) \leq H_{p}(A, C)+H_{p}(C, B)-\inf _{c \in C} p(c, c)$.

Lemma 2 [28] Let $A$ and $B$ be nonempty closed and bounded subsets of a partial metric space $(X, p)$ and $h>1$. Then, for all $a \in A$, there exists $b \in B$ such that $p(a, b) \leq h H_{p}(A, B)$.

The following result was proved by Aydi et al. in [28].

Theorem 1 Let $(X, p)$ be a partial metric space. If $T: X \rightarrow C B^{p}(X)$ is a multi-valued mapping such that, for all $x, y \in X$,

$$
H_{p}(T x, T y) \leq k p(x, y)
$$

where $k \in(0,1)$. Then $T$ has a fixed point.

\section{Main results}

Now, we characterize the celebrated theorem of Kikkawa and Suzuki [33] in the framework of partial metric spaces.

Theorem 2 Define a strictly decreasing function $\Theta$ from $[0,1)$ onto $\left(\frac{1}{2}, 1\right]$ by $\Theta(r)=\frac{1}{1+r}$. Let $(X, p)$ be a complete partial metric space and $F: X \rightarrow C B^{p}(X)$ be a multi-valued mapping. Assume that there exists $r \in[0,1)$ such that

$$
\Theta(r) p(x, F x) \leq p(x, y) \quad \Longrightarrow \quad H_{p}(F x, F y) \leq r p(x, y)
$$

for all $x, y \in X$. Then there exists $u \in X$ such that $u \in F u$.

Proof Let $x_{0} \in X$ be arbitrarily chosen. For all $x_{1} \in F x_{0}$, we have

$$
\Theta(r) p\left(x_{0}, F x_{0}\right) \leq \Theta(r) p\left(x_{0}, x_{1}\right) \leq p\left(x_{0}, x_{1}\right)
$$

and, by the condition (2.1), we get

$$
H_{p}\left(F x_{0}, F x_{1}\right) \leq r p\left(x_{0}, x_{1}\right) .
$$


Let $h \in\left(1, \frac{1}{r}\right)$, by Lemma 2 , there exists $x_{2} \in F x_{1}$ such that $p\left(x_{1}, x_{2}\right) \leq h H_{p}\left(F x_{0}, F x_{1}\right)$. Using the previous inequality, we obtain

$$
p\left(x_{1}, x_{2}\right) \leq h H_{p}\left(F x_{0}, F x_{1}\right) \leq h r p\left(x_{0}, x_{1}\right) .
$$

Now, we have

$$
\Theta(r) p\left(x_{1}, F x_{1}\right) \leq \Theta(r) p\left(x_{1}, x_{2}\right) \leq p\left(x_{1}, x_{2}\right)
$$

and, by the condition (2.1), we get

$$
H_{p}\left(F x_{1}, F x_{2}\right) \leq r p\left(x_{1}, x_{2}\right) .
$$

By Lemma 2, there exists $x_{3} \in F x_{2}$ such that

$$
p\left(x_{2}, x_{3}\right) \leq h H_{p}\left(F x_{1}, F x_{2}\right) \leq h r p\left(x_{1}, x_{2}\right) \leq(h r)^{2} p\left(x_{0}, x_{1}\right) .
$$

Continuing in this way, we can generate a sequence $\left\{x_{n}\right\}$ in $X$ such that $x_{n+1} \in F x_{n}$ and

$$
p\left(x_{n}, x_{n+1}\right) \leq k^{n} p\left(x_{0}, x_{1}\right)
$$

for all $n \in \mathbb{N}$, where $k=h r<1$.

Now, we show that $\left\{x_{n}\right\}$ is a Cauchy sequence. Using (2.2) and the triangle inequality for partial metrics $\left(p_{4}\right)$, for all $n, m \in \mathbb{N}$, we have

$$
\begin{aligned}
p\left(x_{n}, x_{n+m}\right) & \leq p\left(x_{n}, x_{n+1}\right)+p\left(x_{n+1}, x_{n+m}\right)-p\left(x_{n+1}, x_{n+1}\right) \\
& \leq p\left(x_{n}, x_{n+1}\right)+p\left(x_{n+1}, x_{n+m}\right) \\
& \leq p\left(x_{n}, x_{n+1}\right)+p\left(x_{n+1}, x_{n+2}\right)+p\left(x_{n+2}, x_{n+m}\right)-p\left(x_{n+2}, x_{n+2}\right) \\
& \leq p\left(x_{n}, x_{n+1}\right)+p\left(x_{n+1}, x_{n+2}\right)+p\left(x_{n+2}, x_{n+m}\right) .
\end{aligned}
$$

Inductively, we have

$$
\begin{aligned}
p\left(x_{n}, x_{n+m}\right) & \leq p\left(x_{n}, x_{n+1}\right)+p\left(x_{n+1}, x_{n+2}\right)+\cdots+p\left(x_{n+m-1}, x_{n+m}\right) \\
& \leq k^{n} p\left(x_{0}, x_{1}\right)+k^{n+1} p\left(x_{0}, x_{1}\right)+\cdots+k^{n+m-1} p\left(x_{0}, x_{1}\right) \\
& \leq\left(k^{n}+k^{n+1}+\cdots+k^{n+m-1}\right) p\left(x_{0}, x_{1}\right) \\
& \leq \frac{k^{n}}{1-k} p\left(x_{0}, x_{1}\right) \rightarrow 0
\end{aligned}
$$

as $n \rightarrow+\infty$ since $0 \leq k<1$. By the definition of $p^{s}$, we get

$$
p^{s}\left(x_{n}, x_{n+m}\right) \leq 2 p\left(x_{n}, x_{n+m}\right) \rightarrow 0
$$

as $n \rightarrow+\infty$, which implies that $\left\{x_{n}\right\}$ is a Cauchy sequence in $\left(X, p^{s}\right)$. Since $(X, p)$ is complete, by Lemma 1 , the corresponding metric space $\left(X, p^{s}\right)$ is also complete. Therefore, the sequence $\left\{x_{n}\right\}$ converges to some $u \in X$ with respect to the metric $p^{s}$, that is, 
$\lim _{n \rightarrow+\infty} p^{s}\left(x_{n}, u\right)=0$. Again, by Lemma 1 , we have

$$
p(u, u)=\lim _{n \rightarrow+\infty} p\left(x_{n}, u\right)=\lim _{n, m \rightarrow+\infty} p\left(x_{n}, x_{m}\right)=0 .
$$

Next, we show that

$$
p(u, F x) \leq r p(u, x)
$$

for all $x \in X \backslash\{u\}$. Since $p\left(x_{n}, u\right) \rightarrow 0$ as $n \rightarrow+\infty$, there exists $n_{0} \in \mathbb{N}$ such that

$$
p\left(x_{n}, u\right) \leq \frac{1}{3} p(u, x)
$$

for all $n \in \mathbb{N}$ with $n \geq n_{0}$. Then we have

$$
\begin{aligned}
\Theta(r) p\left(x_{n}, F x_{n}\right) & \leq p\left(x_{n}, F x_{n}\right) \leq p\left(x_{n}, x_{n+1}\right) \leq p\left(x_{n}, u\right)+p\left(u, x_{n+1}\right)-p(u, u) \\
& =p\left(x_{n}, u\right)+p\left(u, x_{n+1}\right) \\
& \leq \frac{2}{3} p(u, x) \leq p(u, x)-p\left(x_{n}, u\right) \\
& \leq p\left(x_{n}, x\right)
\end{aligned}
$$

and hence $H_{p}\left(F x_{n}, F x\right) \leq r p\left(x_{n}, x\right)$. Since

$$
\begin{aligned}
p(u, F x) & \leq p\left(u, x_{n+1}\right)+p\left(x_{n+1}, F x\right) \\
& \leq p\left(u, x_{n+1}\right)+H_{p}\left(F x_{n}, F x\right) \\
& \leq p\left(u, x_{n+1}\right)+r p\left(x_{n}, x\right)
\end{aligned}
$$

letting $n \rightarrow+\infty$, we obtain

$$
p(u, F x) \leq r p(u, x)
$$

for all $x \in X \backslash\{u\}$.

Next, we prove that

$$
H_{p}(F x, F u) \leq r p(x, u)
$$

for all $x \in X$ with $x \neq u$. For all $n \in \mathbb{N}$, we choose $v_{n} \in F x$ such that

$$
p\left(u, v_{n}\right) \leq p(u, F x)+\frac{1}{n} p(x, u) .
$$

Then, using (2.4) and the previous inequality, we get

$$
\begin{aligned}
p(x, F x) & \leq p\left(x, v_{n}\right) \leq p(x, u)+p\left(u, v_{n}\right)-p(u, u) \\
& =p(x, u)+p\left(u, v_{n}\right) \\
& \leq p(x, u)+p(u, F x)+\frac{1}{n} p(x, u)
\end{aligned}
$$




$$
\begin{aligned}
& \leq p(x, u)+r p(u, x)+\frac{1}{n} p(x, u) \\
& =\left(1+r+\frac{1}{n}\right) p(x, u)
\end{aligned}
$$

for all $n \in \mathbb{N}$. As $n \rightarrow+\infty$, we obtain $\frac{1}{1+r} p(x, F x) \leq p(x, u)$. From the assumption, we have

$$
H_{p}(F x, F u) \leq r p(x, u)
$$

Finally, if, for some $n \in \mathbb{N}$, we have $x_{n}=x_{n+1}$, then $x_{n}$ is a fixed point of $F$. Assume that $x_{n} \neq x_{n+1}$ for all $n \in \mathbb{N}$. This implies that there exists an infinite subset $J$ of $\mathbb{N}$ such that $x_{n} \neq u$ for all $n \in J$. From

$$
\begin{aligned}
p(u, F u) & \leq p\left(u, x_{n+1}\right)+p\left(x_{n+1}, F u\right) \\
& \leq p\left(u, x_{n+1}\right)+H_{p}\left(F x_{n}, F u\right) \\
& \leq p\left(u, x_{n+1}\right)+r p\left(x_{n}, u\right),
\end{aligned}
$$

letting $n \rightarrow+\infty$ with $n \in J$, we get

$$
p(u, F u)=0=p(u, u)
$$

By Remark 1, we deduce that $u \in F u$ and hence $u$ is a fixed point of $F$. This completes the proof.

It is obvious that Theorem 1 of Aydi et al. follows directly from Theorem 2.

The following theorem is a result of Reich type [36] as well as a generalization of Kikkawa and Suzuki type in the framework of partial metric spaces.

Theorem 3 Let $(X, p)$ be a complete partial metric space and let $F: X \rightarrow C B^{p}(X)$ be a multi-valued mapping satisfying the following:

$$
\theta p(x, F x) \leq p(x, y) \quad \Longrightarrow \quad H_{p}(F x, F y) \leq a p(x, y)+b p(x, F x)+c p(y, F y)
$$

for all $x, y \in X$, nonnegative numbers $a, b, c$ with $a+b+c \in[0,1)$ and $\theta=\frac{1-b-c}{1+a}$. Then $F$ has a fixed point.

Proof Let $h \in\left(1, \frac{1}{a+b+c}\right)$ and $x_{0} \in X$ be arbitrary. Let $x_{1} \in T x_{0}$. By Lemma 2 , there exists $x_{2} \in F x_{1}$ such that

$$
p\left(x_{1}, x_{2}\right) \leq h H_{p}\left(F x_{0}, F x_{1}\right) .
$$

Since $\theta p\left(x_{0}, F x_{0}\right) \leq \theta p\left(x_{0}, x_{1}\right) \leq p\left(x_{0}, x_{1}\right)$, we have

$$
\begin{aligned}
p\left(x_{1}, x_{2}\right) & \leq h H_{p}\left(F x_{0}, F x_{1}\right) \leq h\left(a p\left(x_{0}, x_{1}\right)+b p\left(x_{0}, F x_{0}\right)+c p\left(x_{1}, F x_{1}\right)\right) \\
& \leq h(a+b) p\left(x_{0}, x_{1}\right)+h c p\left(x_{1}, x_{2}\right) \\
& \leq \frac{h(a+b)}{1-h c} p\left(x_{0}, x_{1}\right) .
\end{aligned}
$$


Continuing in a similar way, we can obtain a sequence $\left\{x_{n}\right\}$ of successive approximations for $F$, starting from $x_{0}$, satisfying the following:

(a) $x_{n+1} \in F x_{n}$ for all $n \in \mathbb{N}$;

(b) $p\left(x_{n}, x_{n+1}\right) \leq k^{n} p\left(x_{0}, x_{1}\right)$ for all $n \in \mathbb{N}$,

where $k=\frac{h(a+b)}{1-h c}<1$. Now, proceeding as in the proof of Theorem 2, we deduce that the sequence $\left\{x_{n}\right\}$ converges to some $u \in X$ with respect to the metric $p^{s}$, that is, $\lim _{n \rightarrow+\infty} p^{s}\left(x_{n}, u\right)=0$. Moreover, (2.3) holds by Lemma 2 .

First, we show that

$$
p(u, F x) \leq\left(a+\frac{b}{\theta}\right) p(u, x)+c p(x, F x)
$$

for all $x \in X \backslash\{u\}$. Since $p\left(x_{n}, u\right) \rightarrow 0$ as $n \rightarrow+\infty$ under the metric $p$, there exists $n_{0} \in \mathbb{N}$ such that

$$
p\left(x_{n}, u\right) \leq \frac{1}{3} p(u, x)
$$

for each $n \geq n_{0}$. Then we have

$$
\begin{aligned}
\theta p\left(x_{n}, F x_{n}\right) & \leq p\left(x_{n}, F x_{n}\right) \leq p\left(x_{n}, x_{n+1}\right) \\
& \leq p\left(x_{n}, u\right)+p\left(u, x_{n+1}\right)-p(u, u) \\
& =p\left(x_{n}, u\right)+p\left(u, x_{n+1}\right) \\
& \leq \frac{2}{3} p(u, x) \leq p(u, x)-p\left(x_{n}, u\right) \\
& \leq p\left(x_{n}, x\right),
\end{aligned}
$$

which implies that

$$
\begin{aligned}
H_{p}\left(F x_{n}, F x\right) & \leq a p\left(x_{n}, x\right)+b p\left(x_{n}, F x_{n}\right)+c p(x, F x) \\
& \leq a p\left(x_{n}, x\right)+\frac{b}{\theta} p\left(x_{n}, x\right)+c p(x, F x) \\
& =\left(a+\frac{b}{\theta}\right) p\left(x_{n}, x\right)+c p(x, F x)
\end{aligned}
$$

for all $n \geq n_{0}$. Thus we have

$$
\begin{aligned}
p(u, F x) & \leq p\left(u, x_{n+1}\right)+p\left(x_{n+1}, F x\right) \\
& \leq p\left(u, x_{n+1}\right)+H_{p}\left(F x_{n}, F x\right) \\
& \leq p\left(u, x_{n+1}\right)+\left(a+\frac{b}{\theta}\right) p\left(x_{n}, x\right)+c p(x, F x)
\end{aligned}
$$

for all $n \geq n_{0}$. Letting $n \rightarrow+\infty$, we get

$$
p(u, F x) \leq\left(a+\frac{b}{\theta}\right) p(u, x)+c p(x, F x)
$$

for all $x \in X \backslash\{u\}$. 
Next, we show that

$$
H_{p}(F x, F u) \leq\left(a+\frac{b}{\theta}\right) p(x, u)+c p(u, F u)
$$

for all $x \in X$ with $x \neq u$. Now, for all $n \in \mathbb{N}$, there exists $y_{n} \in F x$ such that

$$
p\left(u, y_{n}\right) \leq p(u, F x)+\frac{1}{n} p(x, u) .
$$

From

$$
\begin{aligned}
p(x, F x) & \leq p\left(x, y_{n}\right) \leq p(x, u)+p\left(u, y_{n}\right)-p(u, u) \\
& =p(x, u)+p\left(u, y_{n}\right) \\
& \leq p(x, u)+p(u, F x)+\frac{1}{n} p(x, u) \\
& \leq p(x, u)+\left(a+\frac{b}{\theta}\right) p(u, x)+c p(x, F x)+\frac{1}{n} p(x, u) \\
& =\left(1+a+\frac{b}{\theta}+\frac{1}{n}\right) p(x, u)+c p(x, F x)
\end{aligned}
$$

for all $n \in \mathbb{N}$, it follows that, as $n \rightarrow+\infty$,

$$
(1-c) p(x, F x) \leq\left(1+a+\frac{b}{\theta}\right) p(x, u)
$$

and so $\theta p(x, F x) \leq p(x, u)$. Thus we have

$$
\begin{aligned}
H_{p}(F x, F u) & \leq a p(x, u)+b p(x, F x)+c p(u, F u) \\
& \leq\left(a+\frac{b}{\theta}\right) p(x, u)+c p(u, F u)
\end{aligned}
$$

for all $x \in X \backslash\{u\}$.

Finally, if, for some $n \in \mathbb{N}$, we have $x_{n}=x_{n+1}$, then $x_{n}$ is a fixed point of $F$. Assume that $x_{n} \neq x_{n+1}$ for all $n \in \mathbb{N}$. This implies that there exists an infinite subset $J$ of $\mathbb{N}$ such that $x_{n} \neq u$ for all $n \in J$. Now, for all $n \in J$, we have

$$
\begin{aligned}
p(u, F u) & \leq p\left(u, x_{n+1}\right)+p\left(x_{n+1}, F u\right) \\
& \leq p\left(u, x_{n+1}\right)+H_{p}\left(F x_{n}, F u\right) \\
& \leq p\left(u, x_{n+1}\right)+\left(a+\frac{b}{\theta}\right) p\left(x_{n}, u\right)+c p(u, F u) .
\end{aligned}
$$

Letting $n \rightarrow+\infty$ with $n \in J$, we get

$$
p(u, F u)=0=p(u, u) .
$$

By Remark 1, we deduce that $u \in F u$ and hence $u$ is a fixed point of $F$. This completes the proof. 
The following theorem is a generalization of a result of Dhompongsa and Yingtaweesittikul [35] to the setting of partial metric space.

Theorem 4 Let $(X, p)$ be a complete partial metric space and let $F: X \rightarrow C B^{p}(X)$ be a multi-valued mapping such that

$$
\theta p(x, F x) \leq p(x, y) \quad \Longrightarrow \quad H_{p}(F x, F y) \leq \lambda(p(x, F x)+p(y, F y))+\mu p(x, y)
$$

for all $x, y \in X$, where $\theta=\frac{1}{2 \lambda+\mu+1}$ with $\lambda$, $\mu$ nonnegative real numbers and $0 \leq 2 \lambda+\mu<1$. Then $F$ has a fixed point.

Proof Let $h \in\left(1, \frac{1}{2 \lambda+\mu}\right)$ and $x_{0} \in X$ be arbitrary. Following the same proof of Theorem 3, by replacing $\theta=\frac{1-b-c}{1+a}$ in the proof by $\theta=\frac{1}{2 \lambda+\mu+1}$, we can obtain a sequence $\left\{x_{n}\right\}$ such that

(a) $x_{n+1} \in F x_{n}$ for all $n \in \mathbb{N}$;

(b) $p\left(x_{n}, x_{n+1}\right) \leq k^{n} p\left(x_{0}, x_{1}\right)$ for all $n \in \mathbb{N}$, where $k=\frac{h(\lambda+\mu)}{1-h \lambda}<1$.

Now, proceeding as in the proof of Theorem 2, we deduce that the sequence $\left\{x_{n}\right\}$ converges to some $u \in X$ with respect to the metric $p^{s}$, that is, $\lim _{n \rightarrow+\infty} p^{s}\left(x_{n}, u\right)=0$. Again, from Lemma 2, we have

$$
p(u, u)=\lim _{n \rightarrow+\infty} p\left(x_{n}, u\right)=\lim _{n \rightarrow+\infty} p\left(x_{n}, x_{m}\right)=0 .
$$

Next, we show that

$$
p(u, F x) \leq \mu p(u, x)+\lambda p(x, F x)
$$

for all $x \in X \backslash\{u\}$. Since $p\left(x_{n}, u\right) \rightarrow 0$ as $n \rightarrow+\infty$, there exists $n_{0} \in \mathbb{N}$ such that $p\left(x_{n}, u\right) \leq$ $\frac{1}{3} p(u, x)$ for all $n \geq n_{0}$. We have

$$
\begin{aligned}
\theta p\left(x_{n}, F x_{n}\right) & \leq p\left(x_{n}, F x_{n}\right) \leq p\left(x_{n}, x_{n+1}\right) \\
& \leq p\left(x_{n}, u\right)+p\left(u, x_{n+1}\right)-p(u, u) \\
& =p\left(x_{n}, u\right)+p\left(u, x_{n+1}\right) \\
& \leq \frac{2}{3} p(u, x) \leq p(u, x)-p\left(x_{n}, u\right) \leq p\left(x_{n}, x\right) .
\end{aligned}
$$

Now, using the conditions (2.6) and (2.7), we obtain

$$
\begin{aligned}
p(u, F x) & \leq p\left(u, x_{n+1}\right)+p\left(x_{n+1}, F x\right) \\
& \leq p\left(u, x_{n+1}\right)+H_{p}\left(F x_{n}, F x\right) \\
& \leq p\left(u, x_{n+1}\right)+\lambda p\left(x_{n}, F x_{n}\right)+\lambda p(x, F x)+\mu p\left(x_{n}, x\right) \\
& \leq p\left(u, x_{n+1}\right)+\lambda p\left(x_{n}, x_{n+1}\right)+\lambda p(x, F x)+\mu p\left(x_{n}, x\right)
\end{aligned}
$$

for all $n \geq n_{0}$. Letting $n \rightarrow+\infty$, we get

$$
p(u, F x) \leq \lambda p(x, F x)+\mu p(u, x),
$$

as desired. 
Next, we show that

$$
H_{p}(F x, F u) \leq \lambda p(x, F x)+\lambda p(u, F u)+\mu p(x, u)
$$

for all $x \in X \backslash\{u\}$. By Lemma 2 , for all $n \in \mathbb{N}$, there exists $y_{n} \in F x$ such that

$$
p\left(u, y_{n}\right) \leq p(u, F x)+\frac{1}{n} p(u, x)
$$

Clearly, we have

$$
\begin{aligned}
p(x, F x) & \leq p\left(x, y_{n}\right) \leq p(x, u)+p\left(u, y_{n}\right)-p(u, u) \\
& =p(x, u)+p\left(u, y_{n}\right) \\
& \leq p(x, u)+p(u, F x)+\frac{1}{n} p(x, u) \\
& \leq p(x, u)+\lambda p(x, F x)+\mu p(u, x)+\frac{1}{n} p(x, u) \\
& \leq\left(1+\mu+\frac{1}{n}\right) p(x, u)+\lambda p(x, F x)
\end{aligned}
$$

for all $n \in \mathbb{N}$. Hence, as $n \rightarrow+\infty$, we get

$$
(1-\lambda) p(x, F x) \leq(1+\mu) p(x, u)
$$

and so $\Theta p(x, F x) \leq p(x, u)$ since $\Theta \leq \frac{1-\lambda}{1+\mu}$. Now, using the condition (2.6), we obtain

$$
H_{p}(F x, F u) \leq \lambda p(x, F x)+\lambda p(u, F u)+\mu p(x, u)
$$

for all $x \in X \backslash\{u\}$.

Finally, if, for some $n \in \mathbb{N}$, we have $x_{n}=x_{n+1}$, then $x_{n}$ is a fixed point of $F$. Assume that $x_{n} \neq x_{n+1}$ for all $n \in \mathbb{N}$. This implies that there exists an infinite subset $J$ of $\mathbb{N}$ such that $x_{n} \neq u$ for all $n \in J$. From

$$
\begin{aligned}
p(u, F u) & \leq p\left(u, x_{n+1}\right)+p\left(x_{n+1}, F u\right) \\
& \leq p\left(u, x_{n+1}\right)+H_{p}\left(F x_{n}, F u\right) \\
& \leq p\left(u, x_{n+1}\right)+\lambda p\left(x_{n}, F x_{n}\right)+\lambda p(u, F u)+\mu p\left(x_{n}, x\right) \\
& \leq p\left(u, x_{n+1}\right)+\lambda \frac{1+\mu}{1-\lambda} p\left(x_{n}, x\right)+\lambda p(u, F z)+\mu p\left(x_{n}, x\right)
\end{aligned}
$$

letting $n \rightarrow+\infty$ with $n \in J$, we get

$$
p(u, F u)=0=p(u, u)
$$

By Remark 1, we deduce that $u \in F u$ and hence $u$ is a fixed point of $F$. This completes the proof.

Now, we give one example to illustrate Theorem 3. 
Example 1 Let $X=\{2,3,4\}$ and $p: X \times X \rightarrow[0,+\infty)$ be a partial metric on $X$ defined by

$$
\begin{aligned}
& p(2,2)=p(3,3)=0, \quad p(4,4)=\frac{9}{20}, \quad p(2,3)=p(3,2)=\frac{2}{5} \\
& p(2,4)=p(4,2)=\frac{1}{2}, \quad p(3,4)=p(4,3)=\frac{9}{19} .
\end{aligned}
$$

Let $F: X \rightarrow C B^{p}(X)$ be defined by

$$
F x= \begin{cases}\{2\} & \text { if } x \in\{2,3\}, \\ \{2,3\} & \text { otherwise. }\end{cases}
$$

It is easy to see that $\{2\}$ and $\{2,3\}$ are closed in $X$ with respect to the partial metric $p$. Now, we have

$$
\begin{aligned}
& H_{p}(F 2, F 2)=H_{p}(F 3, F 3)=H_{p}(F 2, F 3)=H_{p}(\{2\},\{2\})=0 ; \\
& H_{p}(F 4, F 4)=H_{p}(\{2,3\},\{2,3\})=0 ; \\
& H_{p}(F 2, F 4)=H_{p}(F 3, F 4)=H_{p}(\{2\},\{2,3\})=\frac{2}{5} ; \\
& p(2, F 2)=p(2,\{2\})=0 ; \quad p(3, F 3)=p(3,\{2\})=\frac{2}{5} ; \\
& p(4, F 4)=p(4,\{2,3\})=\frac{9}{19} .
\end{aligned}
$$

If we choose $a=\frac{3}{4}, b=\frac{1}{8}$ and $c=\frac{1}{10}$, the multi-valued mapping $F$ satisfies the hypotheses of Theorem 3 and so has a fixed point. To such end, it is enough to show that (2.5) is satisfied in the following cases.

Case 1. $x=2$ and $y=4$. Now, $\theta p\left(2, F_{2}\right) \leq p(2,4)$, where $\theta=\frac{31}{70}$ and

$$
H_{p}(F 2, F 4)=\frac{2}{5} \leq \frac{21}{50} \leq \frac{3}{4} p(2,4)+\frac{1}{8} p(2, F 2)+\frac{1}{10} p(4, F 4) .
$$

Case 2. $x=3$ and $y=4$. Now, $\theta p(3, F 3) \leq p(3,4)$ and

$$
H_{p}(F 3, F 4)=\frac{2}{5} \leq \frac{9}{20} \leq \frac{3}{4} p(3,4)+\frac{1}{8} p(3, F 3)+\frac{1}{10} p(4, F 4) .
$$

Case 3. $x=4$ and $y=3$. Now, $\theta p(4, F 4) \leq p(4,3)$ and

$$
H_{p}(F 4, F 3)=\frac{2}{5} \leq \frac{9}{20} \leq \frac{3}{4} p(4,3)+\frac{1}{8} p(4, F 4)+\frac{1}{10} p(3, F 3) .
$$

Case 4. $x=4$ and $y=2$. Now, $\theta p(4, F 4) \leq p(4,2)$ and

$$
H_{p}(F 4, F 2)=\frac{2}{5} \leq \frac{43}{100} \leq \frac{3}{4} p(4,2)+\frac{1}{8} p(4, F 4)+\frac{1}{10} p(2, F 2) .
$$

Thus all the conditions of Theorem 3 are satisfied. Here $x=2$ is a fixed point of $F$.

On the other hand, the metric $p^{s}$ induced by the partial metric $p$ is given by

$$
\begin{aligned}
& p^{s}(1,1)=p^{s}(2,2)=p^{s}(3,3)=0, \quad p^{s}(2,3)=p^{s}(3,2)=\frac{4}{5} \\
& p^{s}(4,3)=p^{s}(3,4)=\frac{189}{380}, \quad p^{s}(4,2)=p^{s}(2,4)=\frac{11}{20}
\end{aligned}
$$


Note that, in the case of an ordinary Hausdorff metric, the given mapping does not satisfy the condition (2.5). Indeed, for $x=2$ and $y=4$, the condition $\theta p^{s}(2, F 2) \leq p^{s}(2,4)$ is satisfied. But the condition $H(F 2, F 4) \leq a p^{s}(2,4)+b p^{s}(2, F 2)+c p^{s}(4, F 4)$ is not satisfied.

In fact, we have

$$
\begin{aligned}
& H(F 2, F 4)=H(\{2\},\{2,3\})=\frac{4}{5}, \\
& p^{s}(4, F 4)=p^{s}(4,\{2,3\})=\frac{11}{20}
\end{aligned}
$$

and

$$
\frac{4}{5} \geq \frac{3}{4}\left(\frac{11}{20}\right)+\frac{1}{8}(0)+\frac{1}{10}\left(\frac{11}{20}\right)=\frac{187}{400} .
$$

\section{Competing interests}

The authors declare that they have no competing interests.

\section{Authors' contributions}

All authors read and approved the final manuscript.

\section{Author details}

'Department of Mathematics COMSATS, Institute of Information Technology, Chack Shahzad, Islamabad 44000, Pakistan. 2Dipartimento di Matematica e Informatica, Università degli Studi di Palermo, Via Archirafi 34, Palermo, 90123, Italy. ${ }^{3}$ Department of Mathematics Education and RINS, Gyeongsang National University, Jinju, 660-701, Korea. ${ }^{4}$ Department of Mathematics, International Islamic University, Islamabad, Pakistan.

\section{Acknowledgements}

The second author was supported by Università degli Studi di Palermo, Local University Project R. S. ex 60\% and the third author was supported by the Basic Science Research Program through the National Research Foundation of Korea funded by the Ministry of Education, Science and Technology (NRF-2012-0008170).

Received: 6 February 2013 Accepted: 9 June 2013 Published: 3 July 2013

\section{References}

1. Banach, S: Sur les opérations dans les ensembles abstraits et leur application aux équations intégrales. Fundam. Math. 3, 133-181 (1922)

2. Samet, B, Vetro, C, Vetro, P: Fixed point theorems for $\alpha$ - $\psi$-contractive type mappings. Nonlinear Anal. 75, 2154-2165 (2012)

3. Matthews, SG: Partial metric topology. In: Proc. 8th Summer Conference on General Topology and Applications. Ann. New York Acad. Sci., vol. 728, pp. 183-197 (1994)

4. Abdeljawad, T, Karapinar, K, Tas, K: A generalized contraction principle with control functions on partial metric spaces. Comput. Math. Appl. 63, 716-719 (2012)

5. Abdeljawad, T: Fixed points for generalized weakly contractive mappings in partial metric spaces. Math. Comput. Model. 54, 2923-2927 (2011)

6. Altun, I, Erduran, A: Fixed point theorems for monotone mappings on partial metric spaces. Fixed Point Theory Appl. 2011, Article ID 508730 (2011)

7. Altun, I, Sola, F, Simsek, H: Generalized contractions on partial metric spaces. Topol. Appl. 157, 2778-2785 (2010)

8. Aydi, H, Vetro, C, Sintunavarat, W, Kumam, P: Coincidence and fixed points for contractions and cyclical contractions in partial metric spaces. Fixed Point Theory Appl. 2012, 124 (2012)

9. Azam, A, Arshad, M, Jahangir, R: Coincidence points of compatible maps. Indian J. Math. 51, 75-83 (2009)

10. Azam, A, Arshad, M: Fixed points of sequence of locally contractive multivalued maps. Comput. Math. Appl. 57, 96-100 (2009)

11. Di Bari, C, Vetro, P: Fixed points for weak $\phi$-contractions on partial metric spaces. Internat. J. Engin., Contemp. Math. Sci. 1, 5-13 (2011)

12. Di Bari, C, Milojević, M, Radenović, S, Vetro, P: Common fixed points for self-mappings on partial metric spaces. Fixed Point Theory Appl. 2012, 140 (2012)

13. Di Bari, C, Kadelburg, Z, Nashine, H, Radenović, S: Common fixed points of g-quasicontractions and related mappings in 0-complete partial metric spaces. Fixed Point Theory Appl. 2012, 113 (2012)

14. Beg, I, Azam, A: Fixed points of asymptotically regular multivalued mappings. J. Aust. Math. Soc. A 53, 313-326 (1992)

15. Chi, KP, Karapinar, E, Thanh, TD: A generalized contraction principle in partial metric spaces. Math. Comput. Model. 55, 1673-1681 (2012)

16. Cho, YJ, Rhoades, BE, Saadati, R, Samet, B, Shantawi, W: Nonlinear coupled fixed point theorems in ordered generalized metric spaces with integral type. Fixed Point Theory Appl. 2012, 8 (2012) 
17. Cho, YJ, Saadati, R, Wang, S: Common fixed point theorems on generalized distance in order cone metric spaces. Comput. Math. Appl. 61, 1254-1260 (2011)

18. Gordji, ME, Akbartabar, E, Cho, YJ, Ramezani, M: Coupled common fixed point theorems for mixed weakly monotone mappings in partially ordered metric spaces. Fixed Point Theory Appl. 2012, 95 (2012)

19. Graily, E, Vaezpour, SM, Saadati, R, Cho, YJ: Generalization of fixed point theorems in ordered metric spaces concerning generalized distance. Fixed Point Theory Appl. 2011, 30 (2011)

20. Hong, SH: Fixed points of multivalued operators in ordered metric spaces with applications. Nonlinear Anal. 72, 3929-3942 (2010)

21. Hong, SH: Fixed points for mixed monotone multivalued operators in Banach spaces with applications. J. Math. Anal. Appl. 337, 333-342 (2008)

22. Karapinar, E: A note on common fixed point theorems in partial metric spaces. J. Nonlinear Sci. Appl. 5, 74-83 (2012)

23. Karapinar, E: Generalizations of Caristi Kirk's theorem on partial metric spaces. Fixed Point Theory Appl. 2011, 4 (2011)

24. Karapinar, E: Ciric types nonunique fixed point theorems on partial metric spaces. Miskolc Math. Notes 12, 185-191 (2011)

25. Karapinar, E, Erhan, IM: Fixed point theorems for operators on partial metric spaces. Appl. Math. Lett. 24, 1894-1899 (2011)

26. Sintunavarat, $\mathrm{W}$, Cho, YJ, Kumam, P: Coupled fixed point theorems for contraction mapping induced by cone ball-metric in partially ordered spaces. Fixed Point Theory Appl. 2012, 128 (2012)

27. Vetro, F, Radenović, S: Nonlinear $\psi$-quasi-contractions of Ćirić-type in partial metric spaces. Appl. Math. Comput. 219 1594-1600 (2012)

28. Aydi, H, Abbas, M, Vetro, C: Partial Hausdorff metric and Nadler's fixed point theorem on partial metric spaces. Topol. Appl. 159, 3234-3242 (2012)

29. Paesano, D, Vetro, P: Suzuki's type characterizations of completeness for partial metric spaces and fixed points for partially ordered metric spaces. Topol. Appl. 159, 911-920 (2012)

30. Romaguera, S: Fixed point theorems for generalized contractions on partial metric spaces. Topol. Appl. 159, 194-199 (2012)

31. Karapinar, E, Yuksel, U: Some common fixed point theorems in partial metric spaces. J. Appl. Math. 2011, Article ID $263621(2011)$

32. Nadler, S: Multi-valued contraction mappings. Pac. J. Math. 20, 475-488 (1969)

33. Kikkawa, M, Suzuki, T: Three fixed point theorems for generalized contractions with constants in complete metric spaces. Nonlinear Anal. 69, 2942-2949 (2008)

34. Mot, G, Petrusel, A: Fixed point theory for a new type of contractive multivalued operators. Nonlinear Anal. 70 3371-3377 (2009)

35. Dhompongsa, S, Yingtaweesittikul, H: Fixed points for multivalued mappings and the metric completeness. Fixed Point Theory Appl. 2009, 972395 (2009)

36. Reich, S: Fixed point of contractive functions. Boll. Un. Math. Ital. 4, 1-11 (1971)

doi:10.1186/1687-1812-2013-175

Cite this article as: Ahmad et al.: Some fixed point results for multi-valued mappings in partial metric spaces. Fixed Point Theory and Applications 2013 2013:175.

\section{Submit your manuscript to a SpringerOpen ${ }^{\circ}$ journal and benefit from:}

- Convenient online submission

Rigorous peer review

- Immediate publication on acceptance

- Open access: articles freely available online

- High visibility within the field

- Retaining the copyright to your article 